\title{
A AÇÃO AFIRMATIVA E A QUESTÃO DAS QUOTAS RACIAIS
}

\author{
MARCOS CÉSAR BOTELHO*
}

\begin{abstract}
RESUMO: O tema das ações afirmativas é o tema central deste estudo, no qual se buscou tratar dos principais aspectos envolvendo o tema, desde breves considerações históricas, decisões importantes da Suprema Corte Americana, a definição jurídica da expressão ação afirmativa, culminando com uma rápida análise de algumas medidas existentes no ordenamento jurídico brasileiro, bem como o julgamento da ADPF $n^{\circ} 186$, em curso no Supremo Tribunal Federal, que visa apreciar a constitucionalidade ou não da reserva de vagas para negros nas universidades públicas brasileiras.
\end{abstract}

PALAVRAS CHAVES: Ação Afirmativa; Igualdade; Quota; Inclusão.

ABSTRACT: The affirmative acion theme is the central subject of this study, where it was treated about the most important aspects of the matter, involving historical considerations briefly, important decisions from American Supreme Court, the legal definition of the expression affirmative action, finishing with a brief description of some affirmative action's that Brazilian legal system has and the trial of the ADPF $\mathrm{n}^{\circ} 186$, that it allege the unconstitutionality of the racial quotas in public universities, which it will be analyzed by Supremo Tribunal Federal.

KEY-WORDS: Affirmative Action; Equality; Quota; Inclusion.

SUMÁRIO: 1. Das ações afirmativas e a política de quotas; 1.1 Introdução; 1.2 Origem; $1.3 \mathrm{O}$ caso Brown v. Board of Education of Topeka: revisão do princípio separated but equal; 2. Conceito e natureza da ação afirmativa; 3. Das ações afirmativas no Brasil: algumas questões; 4 . Das políticas de quotas raciais nas universidades públicas e o Supremo Tribunal Federal; Conclusões; Bibliografia.

SUMMARY: 1 . The affirmative actions and the policy of quotes; 1.1 Introduction; 1.2 Origin; 1.3 The case Brown v. Board of Education of Topeka: revision of the principle separated but equal; 2. Concept and Nature of the Affirmative Action; 3. The affirmative actions in Brazil: Some Questions; 4. The policy on racial quotes in public universities and the Supremo Tribunal Federal; Conclusions; Bibliography.

Artigo recebido em 26.08.2010. Pareceres emitidos em 25.11.2010 e 15.12.2010.

Artigo aceito para publicação em 6.01.2011.

* Advogado da União, lotado na Coordenação de Patrimônio Público da Procuradoria-Regional da União da $3^{\text {a }}$ Região SP/MS. Ex-Coordenador-Geral de Atos Normativos na CONJUR do Ministério da Defesa. Doutorando em Direito na Instituição Toledo de Ensino - Bauru/SP. Mestre em Direito Constitucional pelo Instituto Brasiliense de Direito Público - Brasília/DF. Professor colaborador na Universidade Estadual do Norte do Paraná (UENP) no Curso de Direito. 


\section{DAS AÇÕES AFIRMATIVAS E A POLÍTICA DE QUOTAS}

\subsection{Introdução}

Tratar das ações afirmativas implica considerar a igualdade material sob um enfoque da diferenciação. Significa que as circunstâncias da realidade são importantes e devem ser consideradas para que se obtenha um tratamento que efetivamente alcance o objetivo, a saber, a promoção da igualdade entre as pessoas.

Consoante adverte Peces-Barba Martínez (2004, p. 186):

La igualdad material debe situarse en el ámbito de la consideración de las circunstancias de la realidad como relevantes o irrelevantes para conseguir un igual peso, para poder alcanzar el objetivo, para poder llegar a ela meta de la independência y de la libertad moral, con un uso adecuado de la libertad social política y jurídica y de los derechos que en Ella se fundan.

Não basta apenas a igualdade formal ou a igualdade perante a lei, mas se impõe a adoção de metas que promovam a igualdade material, referente à redução das desigualdades (VILAS-BÔAS, 2003, p. 20). Assim (VILAS-BÔAS, 2003, p. 21):

Não sendo o princípio da igualdade formal suficiente para se atingir a igualdade, uma vez que não vem acompanhado de institutos hábeis para torná-lo um princípio eficaz, evoluímos para o princípio da igualdade material, o qual decorre da necessidade de tratamento prioritário e diferenciado àqueles grupos ou pessoas que são carecedores da igualdade, em razão de circunstâncias específicas.

Justifica-se esse tratamento tendo em vista que a construção de uma igualdade de fato pressupõe a consideração do indivíduo concreto, pois, segundo Prieto Sanchís (1998, p. 81) ele é o único que pode sofrer uma desigualdade fática, sobretudo se considerarmos que não é possível conceber-se uma justificativa plausível para uma desigualdade jurídica considerando o ser humano in abstracto.

De fato, impor o tratamento desigual para alguém ou determinado grupo traz consigo o ônus da justificativa para aquele que quer promover esse tratamento (ROTHENBURG, 2008, p. 82). Isso porque a igualdade é a regra, sendo o tratamento desigual uma exceção que deve ser justificada ${ }^{1}$, o que se coaduna com a ideia de que a igualdade constitui-se não apenas em um constructo, mas em um processo histórico e dialético ${ }^{2}$. Logo (SANCHÍS, 1998, p. 85):

Las igualdades y desigualdades de hecho no son más que el punto de partida para construir igualdades y desigualdades normativas, cuya justificación no puede apelar solo a la mera facticidad, sino que, partiendo de ésta, há de construirse mediante un ejercicio argumentativo.

\footnotetext{
${ }^{1}$ Consoante escólio de Comanducci (Apud SANCHÍS, 1998, p. 85-86), "la igualdad no tiene necesidad, como tal, de justificación. El deber de justificación pesa, en cambio, sobre las desviaciones de la igualdad.”

${ }^{2}$ Não obstante Rothenburg (2008, p. 82) asseverar que existe uma intrínseca identidade de natureza humana e uma dignidade decorrente dessa condição presente em todos os seres humanos.
} 
Neste contexto, não bastam vedações às discriminações, insuficientes para efetivar uma concretização satisfatória do princípio da igualdade. A ideia de uma promoção da igualdade mediante um non facere, ou seja, com vedações à prática de atos discriminatórios carece de efetividade prática, sobretudo porque não leva em consideração as realidades e contingências locais e de determinada situação histórica.

O Ministro Marco Aurélio de Mello (2006, p. 85) declarou que:

Pode-se afirmar, sem receio de equívoco, que se passou de uma igualização estática, meramente negativa, no que se proibia a discriminação, para uma igualização eficaz, dinâmica, já que os verbos "construir", "garantir”, "erradicar" e "promover" implicam, em si, mudança de óptica, ao denotar "ação”. Não basta não discriminar. É preciso viabilizar - e encontramos, na Carta da República, base para fazê-lo - as mesmas oportunidades. Há de ter-se como página virada o sistema simplesmente principiológico. A postura deve ser, acima de tudo, afirmativa.

Em razão da constatação de insuficiência das medidas de vedação à discriminação é que atualmente é corrente a premissa da obrigatoriedade de diferenciação, o que não significa que as vedações às discriminações não continuam vigentes. (BELLINTANI, 2006, p. 39).

Implica, nas palavras de Leila Pinheiro Bellintani (2006, p. 39-40):

Essa nova dimensão do princípio da igualdade consubstancia-se em mecanismo capaz de fomentar a justiça, tratando os desiguais de acordo com as necessidades que estas desigualdades implicam, colaborando, dessa forma, para a concretização da igualdade substancial, que se pretende efetivamente realizada.

Ou seja (BELLINTANI, 2006, p. 40):

[...] caso as políticas de fomentação da igualdade de oportunidades não sejam suficientes para trazer à realidade uma igualdade de resultados, urge sim a adoção de medidas de discriminação positiva, único meio capaz de introduzir nas sociedades a almejada igualdade substancial ${ }^{3}$.

Essa ideia de diferenciação não se confunde, portanto, com discriminação. Ela traz a noção de que igualdade pode significar, também, respeito às diferenças.

Miguel Carbonell (2003, p. 15) cita o anteprojeto de "Ley Federal para Prevenir y Eliminar la Discriminación”, redigido pela “Comissión Ciudadana de Estudios contra la Discriminación”, apresentado no México no fim de 2001, e que traz a seguinte definição de discriminação:

Para los efectos de esta ley se entenderá por discriminación toda distinción, exclusión o restricción que, basada en el origen étnico o nacional, el sexo, la

\footnotetext{
${ }^{3}$ Para Piovesan (2005, p. 46), “Torna-se, contudo, insuficiente tratar o indivíduo de forma genérica, geral e abstrata. Faz-se necessária a especificação do sujeito de direito, que passa a ser visto em sua peculiaridade e particularidade.”
} 
edad, la discapacidad, la condición social o económica, las condiciones de salud, el embarazo, la lengua, la religión, las opiniones, las preferências sexuales, el estado civil o cualquiera otra, tenga por efecto impedir o anular el reconocimiento o el ejercicio de los derechos fundamentales y la igualdad real de oportunidades de las personas (artículo 4 del anteproyecto).

A Convenção Internacional sobre a Eliminação de Todas as Formas de Discriminação Racial, de 1965 prevê a "discriminação racial” como aquela distinção, exclusão, restrição ou preferência feita com base na raça, cor, descendência ou origem nacional ou étnica, afirmando no artigo $1^{\circ}$, número 4 , in verbis:

Não serão consideradas discriminação racial as medidas especiais tomadas com o único objetivo de assegurar o progresso adequado de certos grupos raciais ou étnicos ou de indivíduos que necessitem da proteção que possa ser necessária para proporcionar a tais grupos ou indivíduos igual gozo ou exercício de direitos humanos e liberdades fundamentais, contanto que tais medidas não conduzam, em consequência, à manutenção de direitos separados para diferentes grupos raciais e não prossigam após terem sido alcançados os seus objetivos.

No mesmo sentido, o artigo $2^{\circ}$ prevê no número 2 a exigência de que os Estados-partes promovam medidas de caráter discriminatório positivo, visando propiciar que determinados grupos raciais ou indivíduos pertencentes a esses grupos, possam, em condições de igualdade, exercer de maneira plena os direitos humanos e liberdades fundamentais, reforçando o caráter temporário de tais medidas.

Portanto, neste contexto em que o direito à igualdade convive com o direito fundamental à diferença, é que desenvolveremos, no presente tópico, o tema das ações afirmativas e seu papel na política de quotas.

\subsection{Origem}

A expressão “ação afirmativa” é originária dos Estados Unidos, surgida na década de 1960, no meio de um turbilhão de reivindicações de natureza democráticas que assolavam aquele país, possuindo como mote central a extensão da igualdade de oportunidade a todos (MOEHLECKE, 2002, p. 198).

Embora a doutrina se refira à decisão proferida pela Suprema Corte Americana no caso Brown v. Board of Education of Topeka, é preciso voltar um pouco no tempo para, de forma breve, delinear alguns fatos importantes que antecederam à supracitada decisão.

Nos Estados Unidos imperou no século XIX um regime de segregação imposto aos negros, decorrentes de diversas leis. Esse regime legal de segregação ficou conhecido como sistema Jim Crow ${ }^{4}$. Logo (KAUFMANN, 2007, p. 137):

\footnotetext{
4 “Em 1843, na Virgínia, formou-se um grupo composto de quatro artistas brancos, chamados Virginia Minstrels. Durante uma apresentação na cidade de Nova Iorque, os componentes do grupo pintaram a pele de preto e realizaram um número de canto - com forte sotaque sulista - e dança, no que acreditavam estarem imitando negros. Esse show fez um grande sucesso e, a partir daí, o grupo passou a excursionar pelas demais cidades. Uma das músicas possuía refrão que terminava com a expressão Jim Crow.” (KAUFMANN, 2007, p. 137)
} 
[...] as normas que vedavam o exercício de muitos direitos aos negros norte-americanos ficaram conhecidas como Leis Jim Crow, e, posteriormente, tal expressão serviu para designar todo o sistema de segregação oficial estadunidense.

Em 1896 a Corte Suprema dos Estados Unidos da América, ao apreciar o caso Plessy v. Ferguson U.S. 537 declarou a constitucionalidade do Estatuto da Louisiana de 1890 que permitia o transporte por estradas de ferro através de acomodações iguais, mas separadas, gerando a doutrina separated but equal, que trazia a ideia de que "[...] o princípio da igualdade não significa que as raças devessem compartilhar do mesmo espaço físico.” (KAUFMANN, 2007, p. 143).

Neste caso, Plessy, que aparentava ser branco, era considerado negro pelo Código da Louisiana, o qual adotava como regra o one drop rule, pela qual uma gota de sangue negra determinava a condição de negro do descendente. No caso de Plessy, dispunha ele de 1/8 de ascendência negra e 7/8 de caucasiana e, acreditando que a maioria do sangue branco lhe conferia tal condição, recusou-se a viajar no vagão destinado apenas a negros, resultando em sua prisão.

Ao apreciar o caso, a Corte da Louisiana rejeitou os motivos de Plessy, que recorreu à Suprema Corte dos Estados Unidos que, porém, confirmou a decisão da Corte Estadual, entendendo que a $13^{\mathrm{a}}$ Emenda proibia a escravidão, não significando a proibição para que organizações privadas ou mesmo indivíduos pudessem promover distinções baseadas na cor. Argumentou ainda, que a lei questionada não estava em conflito com a $14^{\mathrm{a}}$ Emenda, não significando, necessariamente, a inferioridade de uma das raças em relação à outra. Para o Tribunal (KAUFMANN, 2007, p. 143), “[...] a distinção fora efetuada visando a estabelecer maior conforto para as pessoas, no sentido de que a segregação racial terminaria por preservar a paz, além de promover a ordem pública.”

Ademais, argumentou-se que os direitos iguais não poderiam significar necessariamente uma mistura forçada de raças, pois isso deveria ser o resultado de afinidades naturais ${ }^{5}$.

Desde então, embates sociais entre negros e defensores e organizações contrárias a eles permearam a sociedade dos Estados Unidos da América, sendo que diversas organizações criadas em defesa dos negros apresentavam uma postura frontal à hermenêutica que conjugava igualdade com separação, fruto do caso Plessy $v$. Fergusson (KAUFMANN, 2007, p. 158) ${ }^{6}$.

Nesse burburinho social é que John F. Kennedy, então senador, assimila esses ideais de igualdade, e, na sua campanha à Casa Branca, em 1960, alerta para a necessidade de serem enfrentados problemas a que estavam submetidas as classes minoritárias (MENEZES, 2001, p. 87-88).

\footnotetext{
${ }^{5}$ Outras decisões da Suprema Corte dos Estados Unidos aplicaram a doutrina separated but equal, como por exemplo o caso Cumming v. Richmond Country Board of Education e o caso Berea College v. Kentucky. ${ }^{6}$ Segundo Menezes (2001, p. 87), “[...] a partir do final da década de 1950, organizações como a NAACP (National Association for the Advancement of Colored People), expande suas atividades, no mesmo diapasão em que surgem líderes da envergadura de Martin Luther King Jr.”
} 
Em 1961 Kennedy obtém êxito contra seu oponente Richard M. Nixon. Contudo, no início de seu mandato vislumbrou dificuldades na implementação de certos projetos legislativos, já que o Congresso Americano apresentava forte oposição aos seus projetos sociais, o que o levou, diante desse cenário, a adotar medidas que representassem resultados práticos rápidos e que pudessem ser vistos pelo seu eleitorado e, assim, “[...] valeu-se das prerrogativas de seu cargo e, em um primeiro estágio, implementou algumas inovações nos limites do próprio Poder Executivo.” (MENEZES, 2001, p. 88).

Assim (MENEZES, 2001, p. 88) ${ }^{7}$ :

Visando estabelecer uma igualdade de oportunidades e erradicar a discriminação e o preconceito nas relações mantidas entre o governo federal e os seus contratantes, ele expediu, apenas dois meses após assumir a presidência, a Executive Order $\mathrm{n}^{\circ} 10.925$, que, afora criar um órgão para fiscalizar e reprimir a discriminação existente no mercado de trabalho (President's Comittee on Equal Employment Opportunity) empregou pela primeira vez em um texto oficial, ainda que com uma conotação restrita, o termo affirmative action.

Todavia, o termo affirmative action já havia sido utilizado nos Estados Unidos no ano de 1935 segundo relata Leila Pinheiro Bellintani (2006, p. 44) ${ }^{8}$ :

O termo "ação afirmativa” surgiu nos Estados Unidos, em 1935, sob a nomenclatura "affirmative action", quando foi usado no Ato Nacional das Relações de Trabalho, no qual se proibiu ao empregador o cometimento de qualquer forma de repressão contra membros dos sindicatos.

Marco fundamental, porém, que deflagrou esses atos foi a decisão proferida no caso Brown v. Board of Education of Topeka, que analisaremos de forma mais detida no tópico seguinte.

\subsection{0 caso Brown v. Board of Education of Topeka: revisão do princípio separated but equal}

O caso Brown v. Board of Education of Topeka reveste-se de especial importância para a compreensão da questão das ações afirmativas e a mudança de postura adotada pela Suprema Corte Americana com relação à doutrina dos separados mais iguais, defendida em Plessy v. Fergusson.

Questão curiosa é que o início do julgamento ocorreu ainda quando a presidência estava a cargo do Justice Vinson da Corte Suprema, o qual não estava totalmente convencido da necessidade de modificação do entendimento estabelecido em Plessy v. Fergusson, situação que acabou por arrastar o caso. Todavia, com o falecimento inesperado de Vinson, o Justice Earl Warren chegou à presidência da Suprema Corte,

\footnotetext{
${ }^{7}$ No mesmo sentido: MOEHLECKE, 2002, p. 198.

${ }^{8}$ No mesmo sentido: VILAS-BÔAS, 2003, p. 33. Conforme Vilas-Bôas (2003, p. 33), “Com o falecimento de Kennedy, o presidente Lyndon Johnson promoveu mais um avanço na intenção de criar mecanismos de combate à desigualdade. Mediante a Ordem Executiva 11246. Este presidente norte-americano veio a estimular que aquelas firmas contratadas pelo governo buscassem a ação afirmativa, visando a garantir a igualdade de oportunidades aos membros provenientes das minorias raciais e dos deficientes físicos, proibindo a discriminação.”
} 
iniciando um período de grande ativismo daquele Tribunal (KAUFMANN, 2007, p. 160; MENEZES, 2001, p. 81) ${ }^{9}$.

Dessa forma, somente no ano de 1954 é que a Suprema Corte dos Estados Unidos, pela primeira vez desde Plessy v. Fergusson (1986) permitiu que houvesse a revisão total da questão, prolatando decisão que é considerada marco no direito constitucional norte-americano (MENEZES, 2001, p. 80).

O caso envolveu, em realidade, quatro processos distintos, nos quais os recorrentes eram estudantes negros que pleiteavam, com fundamento no princípio da igualdade, o acesso a certas instituições públicas de ensino, sem a necessidade de observar a segregação que lhes era imposta por leis locais ${ }^{10}$.

Particularmente, em relação ao caso Brown v. Board of Education of Topeka, os requerentes eram crianças negras com idade para frequentar escola primária, residentes em Topeka e que haviam intentado ação no Tribunal Federal do Distrito de Kansas com o desiderato de impedir que houvesse a aplicação de lei do Kansas que permitia, embora não impusesse, que as cidades com mais de 15.000 (quinze mil) habitantes mantivessem facilidades escolares separadas para estudantes negros e brancos.

O Tribunal Federal do Kansas, embora admitindo que a segregação no ensino público tenha efeito prejudicial para as crianças negras, julgou improcedente o pedido sob o argumento de que as escolas para negros e brancos eram substancialmente iguais no tocante a edifícios, transportes, planos de estudo e qualificação profissional dos professores.

Nota-se, portanto, que a decisão do Tribunal Federal do Kansas baseou-se na doutrina dos separados mas iguais, valendo-se, portanto, do solidificado conceito de segregação, o qual fundamentava-se na possibilidade de discriminação desde que as facilidades fornecidas a negros e brancos fossem equivalentes (HARTMAN; MERSKY; TATE, 2004, p. 36)

Avaliando a construção jurisprudencial da $14^{\text {a }}$ Emenda, o Justice Warren asseverou que a doutrina dos separados mais iguais, construída em Plessy v. Fergusson tratava não do ensino, mas do transporte. Contudo, desde a sua prolação até o julgamento de Brown v. Board of Education of Topeka, em 1954, a Corte Suprema dos Estados Unidos havia apreciado outros seis casos envolvendo o campo do ensino público (SUB JUDICE, 1998, p. 78).

Conforme manifestou Warren (SUB JUDICE, 1998, p. 79):

Nos casos presentes, a questão põe-se directamente. Aqui, ao contrário do caso Sweatt $v$. Painter, existem conclusões no sentido de que as escolas para negros e brancos envolvidas foram equiparadas, ou então a sê-lo, no que toca a edifícios, planos de estudos, qualificações e salários dos professores e

\footnotetext{
9 “[...] a doutrina separados mais iguais perdurou durante quase um século, até ser afastada no julgamento de processos que tinham por objeto justamente o tema no qual ela se originou: a segregação racial adotada nas instituições de ensino.” (MENEZES, 2001, p. 80).

${ }^{10}$ Os casos eram: Brown v. Board of Education of Topeka, Briggs v. Elliott, Davis v. County School Board e Gebbart v. Belton. Ver: HARTMAN; MERSKY; TATE, 2004, p. 36.
} 
outros factores tangíveis. A nossa decisão, contudo, não pode apoiar-se numa mera comparação destes factores tangíveis das escolas para negros e brancos envolvidas em cada um dos casos. Devemos antes olhar para as conseqüências da própria segregação no ensino público.

Ainda, segundo Warren (SUB JUDICE, 1998, p. 79):

Hoje, a educação é talvez a mais importante função dos estados e dos governos locais. As leis sobre a freqüência obrigatória da escola e as enormes despesas com o ensino, mostram a importância que damos ao ensino na nossa sociedade democrática. [...] Hoje em dia é duvidoso que se possa esperar o sucesso de qualquer criança na sua vida futura se lhe for negada a oportunidade da instrução. Tal oportunidade, onde é garantida pelo Estado, é um direito que deve estar à disposição de todos em termos iguais.

E, com base nisso, Warren entendeu que uma segregação das crianças nas escolas públicas com base tão-somente na raça, mesmo que outros fatores tangíveis, tais como instalações físicas, fossem iguais, priva essas crianças do grupo minoritário de iguais oportunidades de ensino. (SUB JUDICE, 1998, p. 79).

Com base nessas ponderações o Justice Warren concluiu que, “[...] no campo da educação a doutrina 'separate but equal' não tem lugar. É inerentemente desigual separar por facilidades educacionais. ${ }^{11 \text { ” }}$

Logo, a Suprema Corte Americana, no julgamento Brown v. Board of Education of Topeka acabou por conferir uma nova dimensão ou novo sentido à cláusula de igual proteção segundo as leis, conforme prevista na $14^{\mathrm{a}}$ Emenda (KAUFMANN, 2007, p. 161). Outro elemento importante é que o Justice Warren ressaltou a necessidade de que a Corte Suprema não atrasasse o relógio para 1868 quando a $14^{\mathrm{a}}$ Emenda foi adotada, nem para 1896 quando a decisão Plessy $v$. Fergusson fora prolatada, exigindo-se da Corte a apreciação do caso à luz do atual estágio de desenvolvimento da educação pública e o seu lugar na vida americana atual (MENEZES, 2001, p. 84).

Um ano após o julgamento do caso Brown v. Board of Education of Topeka, a Suprema Corte dos Estados Unidos deparou-se novamente com a questão no caso que ficou conhecimento como Brown II (Brown v. Board of Education II, 349 US 294), decorrente de demanda interposta pela NAACP visando que a Corte pronunciasse acerca dos termos em que deveria se ter o início do fim da era de segregação, a saber, sobre a forma de efetivação da decisão anterior (KAUFMANN, 2007, p. 161).

A Corte, ao apreciar o primeiro caso, "[...] entendeu que a ruptura com a doutrina separatista deveria ocorrer de maneira lenta, paulatina e gradual, mas, de maneira ambígua, não fixou prazo, nem etapas, a serem cumpridas.” (KAUFMANN, 2007, p. 161).

Todavia, quando da apreciação do caso Brown II, a Corte encontrou forte resistência nas escolas públicas estaduais, havendo, diversas tentativas de obstaculizar

${ }^{11}$ Tradução livre de: "We conclude that in the field of education the doctrine of "separate but equal" has no place. Separate educational facilities are inherently unequal." (Apud HARTMAN; MERSKY; TATE, 2004, p. 38) 
o cumprimento do julgado, com atos que incluíram a omissão, o desafio a líderes negros e a edição de novas leis estaduais com intuito segregacionista (KAUFMANN, 2007, p. 162).

Diante desse quadro, a Corte, a fim de preservar a sua autoridade e credibilidade, atuou com rigor (KAUFMANN, 2007, p. 162) ${ }^{12}$ :

“[...] consignando que o desrespeito às decisões emanadas da Corte significaria a ruptura da própria ordem constitucional e que nenhum tipo de atraso ou prorrogação para promover a integração dos negros nas escolas seria admissível, ainda que de boa-fé.”

A importância do caso Brown v. Board of Education of Topeka, transcendeu as questões relativas à educação, acabando por influenciar outros segmentos da sociedade, em julgamentos posteriores, em situações que envolveram praticamente instalações públicas ou quase públicas (KAUFMANN, 2007, p. 163) ${ }^{13}$.

\section{CONCEITO E NATUREZA DA AÇÃO AFIRMATIVA}

Como visto alhures, as ações afirmativas nasceram nos Estados Unidos com o desiderato principal de implementar uma maior inclusão social dos grupos historicamente discriminados.

Dessa forma, a ação afirmativa assumiu diversas formas, conforme assevera Moehlecke (2002, p. 199), citando como exemplo, as ações voluntárias, as de caráter obrigatório ou, ainda, estratégias mistas, programas governamentais, como o caso no Brasil do Decreto $\mathrm{n}^{\circ}$ 4.228, de 13 de maio de 2002, que instituiu no âmbito da Administração Pública Federal o Programa Nacional de Ações Afirmativas, programas privados, leis, orientações decorrentes de decisões jurídicas e agências de fomento e regulação. Assim (BELLINTANI, p. 2006, p. 41):

[...] tais mecanismos de inclusão social, já espalhados por todo o mundo, além de promoverem maior participação dessas categorias discriminadas, são vistos como instrumentos que possuem o condão de implementar maior igualdade social de um modo geral.

\footnotetext{
${ }^{12}$ Cite-se, ainda, o caso Alexander v. Holmes County Board of Education, que o Tribunal asseverou que “A Corte de apelação deveria ter negado todos os pedidos para obtenção de mais tempo, porque constitucionalmente não seriam mais permitidas as contínuas operações contrárias à integração com base no preceito ‘o mais breve possível' das escolas segregatórias. Sob explícitas determinações desta Corte, a obrigação de cada distrito escolar é de acabar com o sistema dualista de uma vez e operar, a partir de agora, e daqui por diante, apenas escolas unitárias.” (Apud KAUFMANN, 2007, p. 163). Veja-se, ainda, MacNeese v. Board of Education, onde a Suprema Corte passou a admitir não mais o prévio esgotamento das instâncias administrativas para os casos referentes à segregação em escolas públicas como requisito para que os casos fossem conhecidos pelas Cortes Federais.

${ }^{13}$ Como exemplo, tem-se Muir v. Luisville Park Theatrical Ass'n 347 US 971, Maynor of Baltimore v. Dawson 350 US 877, Gayle v. Browder 352 US 903, State Athletic Com'n v. Dorsey 359 US 533, Turner v. City of Memphis 369 US 530, Johnson v. Virginia 373 US 61 e Schiro v. Bynum 375 US 395. (Cf. MENEZES, 2001, p. 85)
} 
Importante salientar que o Equal Employment Opportunity Comission - EEOC, instituído em 6 de março de 1961 pelo Presidente John Kennedy, por intermédio da Ordem Executiva $\mathrm{n}^{\circ} 10.925$, apesar de ter utilizado a expressão affirmative action, buscava equacionar apenas medidas de combate à discriminação (KAUFMANN, 2007, p. 169).

Para Kellough (2006, p. 3), a expressão “ação afirmativa é um termo muito familiar entre muitos americanos, sendo, porém, pouco compreendido. Segundo ele, o termo “[...] tem significado uma variedade de estratégias designadas para aumentar o emprego, a educação e oportunidades de negócios para grupos, tais como minorias étnicas ou raciais e mulheres, que têm sofrido discriminação.” (KELLOUGH, 2006, p. 3)

Já, Flávia Piovesan (2005, p. 49) ao tratar das ações afirmativas assevera que:

Elas constituem medidas especiais e temporárias que, buscando remediar um passado discriminatório, objetivam acelerar o processo com o alcance da igualdade substantiva por parte de grupos vulneráveis, como as minorias étnicas e raciais e as mulheres, entre outros grupos.

William L. Taylor (Apud MOEHLECKE, 2002, p. 201) faz uma distinção entre ação afirmativa, reparação e distribuição, dispondo que:

O primeiro, necessariamente, inclui como beneficiários de seus programas todos os membros do grupo prejudicado. O segundo, por sua vez, pressupõe como critério suficiente (ou mesmo exclusivo) a carência econômica ou socioeconômica dos membros do grupo em questão, independentemente dos motivos dessa carência. A ação afirmativa diferenciar-se-ia, no primeiro caso, porque “... em programas de ação afirmativa, o pertencimento a um determinado grupo não é suficiente para que alguém seja beneficiado; outros critérios iniciais de mérito devem ser satisfeitos para que alguém seja qualificado para empregos ou posições...”. Já em relação à distribuição, ela distingue-se por configurar-se em medida de justiça, a qual constitui-se em argumento legal para seu pleito, tal como a jurisprudência norte-americana a consagrou.

Neste viés, para Taylor (Apud MOEHLECKE, 2002, p. 201) teria uma função precípua de promover iguais oportunidades para as pessoas ou grupos vitimados por discriminação.

Considerando o contexto brasileiro, Roberta Fragoso Menezes Kaufmann (2007, p. 220) propõe a seguinte definição de ação afirmativa:

Podemos conceituar as ações afirmativas como um instrumento temporário de política social, praticado por entidades privadas ou pelo governo, nos diferentes poderes e nos diversos níveis, por meio do qual se visa a integrar certo grupo de pessoas à sociedade, objetivando aumentar a participação desses indivíduos sub-representados em determinadas esferas, nas quais tradicionalmente permaneceriam alijados por razões de raça, sexo, etnia, deficiências física e mental ou classe social. 
O ponto interessante a ser destacado na definição de Kaufmann está no fato de ligar as ações afirmativas não apenas ao governo, mas também a entidades privadas, significando que as ações afirmativas não são instrumentos da política estatal, embora não se possa deixar de considerar que o Estado é o principal agente para fomento dessas ações, mas pode ser um instrumento posto à disposição de entidades privadas ${ }^{14}$.

Saliente-se que são diversos os instrumentos existentes para promoção das ações afirmativas. Segundo Moehlecke (2002, p. 199), a ação afirmativa, em razão da complexidade dos contextos que se lhe apresentam, acabou por assumir diversas formas, tais como ações de natureza voluntária, de caráter obrigatório, estratégias mistas, programas governamentais ou privados, dentre outros.

Kellough (2006, p. 3) afirmou que as ações afirmativas podem ser implementadas de diversas maneiras, de acordo com as exigências sociais do momento.

No Brasil, por exemplo, podemos citar o disposto no artigo $2^{\circ}$, inciso III do Decreto $n^{\circ}$ 4.228, de 2002 que instituiu no âmbito da Administração Pública Federal o Programa Nacional de Ações Afirmativas, o qual prevê que este programa contemplará, dentre outras coisas, a observância, nas licitações levadas a cabo pelo poder público federal, a obrigatoriedade de fixação de critério adicional de pontuação a ser utilizado para beneficiar fornecedores que comprovem a adoção de políticas compatíveis com os objetivos do Programa.

Tecidas estas considerações relativas ao conceito de ação afirmativa, surge a questão de se saber se são medidas compensatórias ou distributivas.

Segundo Moehlecke (2002, p. 201), “[...] a ação afirmativa não é especificamente uma política compensatória redistributiva, pois ela exige que a carência socioeconômica dos indivíduos seja identificada como conseqüência da discriminação racial, étnica ou sexual, seu problema central.”

Flávia Piovesan (2005, p. 49), a outro giro, afirma que, “As ações afirmativas, como políticas compensatórias adotadas para aliviar e remediar as condições resultantes de um passado de discriminação, cumprem uma finalidade pública decisiva para o projeto democrático.”

Para Edward Kellogh (2006, p. 12), as ações afirmativas podem ser compreendidas sob um viés de redistribuição de oportunidades, visando justamente atingir aqueles que sofreram desvantagens em razão da raça, por motivos étnicos, sexo ou quaisquer outras circunstâncias, asseverando, inclusive, que esse aspecto redistributivo é mais vulnerável às críticas, pois “[...] a existência de preferências contradiz o conceito de igualdade pura de oportunidades.” (KELLOGH, 2006, p. 12)

\footnotetext{
${ }^{14}$ Outros conceitos podem ser mencionados, como por exemplo, o de Vilas-Bôas, para quem “Ações afirmativas são medidas temporárias e especiais, tomadas ou determinadas pelo Estado, de forma compulsória ou espontânea, com o propósito específico de eliminar as desigualdades que foram acumuladas no decorrer da história da sociedade.” (VILAS-BÔAS, 2003, p. 29); Para Bellintani (2006, p. 49), “Através da análise dos diversos conceitos colacionados, percebe-se que os autores são unânimes em afirmar que tais medidas visam combater as desigualdades e implantar maior isonomia substancial entre os membros de uma mesma sociedade. Esse objetivo consubstancia-se, justamente, no principal fundamento para a adoção das ações afirmativas,"
} 
Neste contexto, o melhor entendimento aponta não para uma simples redistribuição de bens ou recursos, pois não se pode confundir ação afirmativa com medidas de caráter assistencial. O objetivo das ações afirmativas não é redistribuir riqueza, mas sim, propiciar a igualdade de oportunidades, com vistas ao fomento de uma igualdade substancial. Ela busca promover o reconhecimento de determinada pessoa ou grupo.

A ausência de igualdade de oportunidades torna certos grupos minoritários ou pessoas em categorias inferiores, ocasionando o desmantelamento de sua própria identidade, levando a indeterminação da auto-realização individual a que alude Axel Honneth, capaz de gerar um sofrimento que se irradia para a esfera da liberdade (HONNETH, 2007, p. 41). Para Honneth (2007, p. 128):

[...] os membros das famílias chegam à auto-realização em suas inclinações e carências se e somente se eles se concederem entre si um tipo de cumplicidade e assistência que exprima o reconhecimento da insubstituibilidade do outro.

Nancy Fraser (2003, p. 2), na mesma esteira, afirmou que:

De facto, hoje em dia, a reivindicação de reconhecimento é a força impulsionadora de muitos conflitos sociais, desde batalhas sobre o multiculturalismo a lutas sobre as relações sociais de sexo e a sexualidade, desde campanhas pela soberania nacional e autonomia subnacional a esforços para construir organizações políticas transnacionais, desde a jihad fundamentalista aos revivescentes movimentos internacionais de direitos humanos.

Destarte, essa busca por reconhecimento, como alertaram Honneth e Fraser, impõe medidas ou políticas capazes de compensar aqueles grupos que historicamente sofreram segregação e discriminação, levando-os a uma situação de inferioridade. Tais políticas visam compensar essa desigualdade de oportunidades, justamente para fornecer a estes grupos ou pessoas as possibilidades de participação igual nos atos da vida, com vistas à promoção de seu bem-estar e inclusão.

Importante, porém, salientar que ação afirmativa não se confunde com discriminação positiva, conforme ensinamento de Leila Pinheiro Bellintani (2006, p. 52) para quem "[...] todo aquele mecanismo que tiver por escopo fomentar maior isonomia propiciando a aquisição igualitária dos bens da vida pode encaixar-se perfeitamente na conceituação de ação afirmativa.”

No entender de Bellintani (2006, p. 53-54):

[...] na realidade norte-americana, o termo ação afirmativa é utilizado para denominar qualquer mecanismo que vise maior inclusão dos historicamente discriminados, assim como ocorre no Brasil. Na Europa, por sua vez, doutrinadores, cientes de que existem mecanismos de ação afirmativa que promovem a igualdade, mas que, por vezes, implicam a adoção de alguma discriminação positiva, vêem nas ações afirmativas um gênero do qual as discriminações positivas são espécie. 
Neste sentido, todas as discriminações positivas são uma ação afirmativa; contudo, nem toda a ação afirmativa pode ser considerada uma medida de discriminação positiva.

\title{
3. DAS AÇÕES AFIRMATIVAS NO BRASIL: ALGUMAS QUESTÕES
}

No Brasil, algumas medidas de natureza legislativa foram tomadas a partir de 1988 visando estabelecer algumas políticas de ação afirmativa. Neste tópico estaremos fazendo uma breve análise de três, a saber, a política de quotas e a reserva do artigo 37, inciso VIII da Constituição Federal, a Lei no 9.100, de 29 de setembro de 1995, também conhecida como Lei das Quotas e o Decreto $\mathrm{n}^{\circ} 4.228$, de 2002, que instituiu no âmbito da Administração Pública Federal o Programa Nacional de Ações Afirmativas.

No caso do artigo 37, inciso VIII, estamos diante de previsão de implementação de ações afirmativas visando estabelecer quotas para pessoas com deficiência. O dispositivo prescreve, in verbis:

\author{
Art. 37. Omissis. \\ $[\ldots]$ \\ VIII - a lei reservará percentual dos cargos e empregos públicos para as \\ pessoas portadoras de deficiência e definirá os critérios de sua admissão.
}

Conforme se vê, a norma impõe a obrigatoriedade de lei prevendo percentual de cargos e empregos públicos para as pessoas com deficiência, inclusive com a previsão de critérios para sua admissão.

Sobre o dispositivo, o Supremo Tribunal Federal pronunciou-se dizendo que a exigência prevista no inciso VIII do artigo 37 da Carta Fundamental subsiste mesmo que o percentual legalmente previsto seja inferior a um, sendo que, nestes casos, impõe-se o arredondamento da fração, buscando-se assim, garantir a eficácia do supracitado dispositivo ${ }^{15}$.

O caráter da reserva prevista no artigo 37, inciso VIII da Lei Fundamental não significa afastar a regra geral de aprovação em concurso público. Neste sentido, o aresto abaixo:

Concurso público. Candidata reprovada. A exigência de caráter geral, de aprovação em concurso, não pode ser afastada nem mesmo pela reserva de "percentual dos cargos e empregos públicos para as pessoas portadoras de deficiência” (CF, art. 37, II e VIII) ${ }^{16}$.

Para Luiz Alberto David Araújo (2008, p. 915), a norma não significa uma porta aberta para o serviço público, pois existem critérios que devem ser observados para o ingresso pela pessoa com deficiência. Assim, a pessoa com deficiência deve estar habilitada para o cargo, o que significa saber se a sua deficiência é compatível com o cargo em questão, sendo uma "regra de interpretação natural para a questão" (ARAÚJO, 2008, p. 915).

${ }^{15}$ STF, RE 227.299, Rel. Min. Ilmar Galvão, julgamento em 14.06.2000, DJ de 6.10.2000.

${ }^{16}$ STF, MI 153-AgR, Rel. Min. Paulo Brossard, julgamento em 14.03.1990, DJ de 30.03.1990. 
Ademais, assevera Araújo (2008, p. 915), a pessoa com deficiência “[...] deve ser aprovada em concurso público", impondo a necessidade, portanto, de que a pessoa com deficiência demonstre possuir a competência mínima exigida, quando, somente então, terá o benefício a que alude o artigo 37, inciso VIII da Constituição Federal.

Daí, concluir Luiz Alberto David Araújo (2008, p. 915):

Portanto, podemos afirmar que há dois requisitos que devem ser atendidos pelo candidato: superar a nota mínima e ter compatibilidade com o cargo (ou seja, a deficiência não pode ser um impeditivo para o cargo). O restante é um benefício na classificação, que revela a política pública constitucional.

A Lei $\mathrm{n}^{\circ}$ 9.100, de 29 de setembro de 1995 estabeleceu normas para a realização das eleições de 3 de outubro de 1996. Em seu artigo 11, caput, o texto previa que cada partido ou coligação poderia registrar candidatos para a Câmara Municipal até cento e vinte por cento do número de lugares a preencher. Significa, por exemplo, que uma Câmara que oferecesse 10 (dez) vagas, permitiria que o partido ou a coligação registrassem até 120 (cento e vinte) candidatos.

Todavia, a grande novidade foi prevista no $\S 3^{\circ}$ do artigo 11 da Lei $n^{\circ} 9.100$, de 1995, que prescreveu a obrigatoriedade de que os partidos ou coligações reservassem no mínimo 20\% das vagas para preenchimento por candidaturas de mulheres.

Esse percentual foi alterado posteriormente pela Lei $\mathrm{n}^{0} 9.504$, de 30 de setembro de 1997, que no artigo 10, § $3^{\circ}$ prevê, in verbis:

\section{Art. 10. Omissis.}

$[\ldots]$

$\S 3^{\circ}$ Do número de vagas resultante das regras previstas neste artigo, cada partido ou coligação preencherá o mínimo de 30\% (trinta por cento) e o máximo de $70 \%$ (setenta por cento) para candidaturas de cada sexo.

A alteração promovida pelo artigo 10 acima citado é salutar e corrigi falha no texto do artigo $11, \S 3^{\circ}$ da Lei $n^{\circ} 9.100$, de 1995 . Isso porque este dispositivo previa apenas a exigência de fixação de, no mínimo, 20\% das vagas para preenchimento por candidaturas de mulheres. Ao não fixar um máximo e, vincular apenas as mulheres, a Lei das Quotas abriu a possibilidade de que houvesse um partido ou coligação com $100 \%$ de mulheres ou com um percentual capaz de reduzir as candidaturas dos homens a um patamar inferior a $20 \%$, gerando um resultado nefando, a saber, uma discriminação não permitida pela Constituição Federal.

Com o artigo 10, $\S 3^{\circ}$ da Lei ${ }^{\circ}$ 9.504, de 1997, há referência a expressão “cada sexo”, o que significa que é garantido tanto aos homens, quanto as mulheres, pelo menos 30\% das vagas para as candidaturas.

Em maio de 2002 foi editado o Decreto $n^{\circ}$ 4.228, que instituiu no âmbito da Administração Pública Federal o Programa Nacional de Ações Afirmativas. Segundo o artigo $1^{\circ}$ deste Decreto, a coordenação ficaria a cargo da Secretaria de Estado dos Direitos Humanos do Ministério da Justiça. 
O artigo $2^{\circ}$ prevê que o Programa Nacional de Ações Afirmativas contemplará diversas medidas na área administrativa e de gestão estratégica. Dentre elas, prevê a seguintes ações previstas nos incisos I a VI do dispositivo, in verbis:

Art. $2^{\circ}$ Omissis.

I - observância, pelos órgãos da Administração Pública Federal, de requisito que garanta a realização de metas percentuais de participação de afrodescendentes, mulheres e pessoas portadoras de deficiência no preenchimento de cargos em comissão do Grupo-Direção e Assessoramento Superiores - DAS;

II - inclusão, nos termos de transferências negociadas de recursos celebradas pela Administração Pública Federal, de cláusulas de adesão ao Programa;

III - observância, nas licitações promovidas por órgãos da Administração Pública Federal, de critério adicional de pontuação, a ser utilizado para beneficiar fornecedores que comprovem a adoção de políticas compatíveis com os objetivos do Programa; e

IV - inclusão, nas contratações de empresas prestadoras de serviços, bem como de técnicos e consultores no âmbito de projetos desenvolvidos em parceria com organismos internacionais, de dispositivo estabelecendo metas percentuais de participação de afrodescendentes, mulheres e pessoas portadoras de deficiência.

As medidas visam os grupos afrodescendentes, mulheres e pessoas com deficiência. Para atingir estes grupos vulneráveis, instituiu-se o Comitê de Avaliação e Acompanhamento do Programa Nacional de Ações Afirmativas, o qual teria, dentre outras atribuições relativas à gestão do programa, o de promover, no âmbito da Administração Pública Federal, a sensibilização dos servidores públicos para a necessidade de proteger os direitos humanos e eliminar as desigualdades de gênero, raça e as que se vinculam às pessoas com deficiência.

\section{DAS POLÍTICAS DE QUOTAS RACIAIS NAS UNIVERSIDADES PÚBLICAS E O SUPREMO TRIBUNAL FEDERAL}

A questão das quotas raciais ou sistema de reserva de vagas encontra-se em análise no âmbito do Supremo Tribunal Federal, na Argüição de Descumprimento de Preceito Fundamental - ADPF $n^{\circ} 186$, proposta pelo Partido Democratas - DEM, protocolizada em 20 de julho de 2009 e no Recurso Extraordinário n 597.285-2, protocolizada em 10 de fevereiro de 2009, ambos da relatoria do Ministro Ricardo Lewandowski. Isso demonstra que a questão encontra-se judicializada na seara do Pretório Excelso há pouco tempo.

No caso do Recurso Extraordinário n ${ }^{\circ}$ 597.285-2, o Pleno do Tribunal reconheceu a repercussão geral da matéria em decisão proferida em 27 de setembro de 2009, publicada em 09 de outubro de 2009. O caso envolveu recorrente que não alcançou classificação suficiente em exame vestibular para fins de admissão em curso superior de Administração, embora tenha obtido pontuação maior do que alguns candidatos que ingressaram no mesmo curso pelo sistema de quotas.

Assim, no Recurso Extraordinário em questão discute-se a constitucionalidade do sistema de reserva de vagas como forma de ação afirmativa de inclusão social. 
Em relação à $A D P F n^{\circ} 186$, houve indeferimento da liminar pela presidência, em decisão proferida em 31 de julho de 2009, ocorrendo sua distribuição ao Ministro Ricardo Lewandowski em 04 de agosto do mesmo ano.

A questão mais importante envolvendo, por ora, estas duas ações é que, em despacho de 15 de setembro de 2009 o relator, com fulcro no artigo $9^{\circ}$, $\S 1^{\circ}$ da Lei $\mathrm{n}^{\circ}$ 9.868, de 10 de novembro de 1999 e art. 21, inciso XVII do Regimento Interno do Supremo Tribunal Federal, convocou audiência pública que se realizou nos dias 3 a 5 de março de 2010. Segundo consta do edital ${ }^{17}$ :

O debate em questão consubstancia-se na constitucionalidade do sistema de reserva de vagas, baseado em critérios raciais, como forma de ação afirmativa de inclusão no ensino superior.

A questão constitucional apresenta relevância do ponto de vista jurídico, uma vez que a interpretação a ser firmada por esta Corte poderá autorizar, ou não, o uso de critérios raciais nos programas de admissão das universidades brasileiras.

Além disso, evidencia-se a repercussão social, porquanto a solução da controvérsia em análise poderá ensejar relevante impacto sobre políticas públicas que objetivam, por meio de ações afirmativas, a redução de desigualdades para o acesso ao ensino superior.

Ficam, assim, designados os dias de 3 a 5 de março de 2010, das 9h às $12 \mathrm{~h}$, para a realização da audiência pública, nas dependências do Supremo Tribunal Federal.

Assim, o Supremo Tribunal Federal deu importante passo, ao trazer a discussão com os diversos atores sociais interessados no deslinde da causa, seja favoravelmente ou não.

Tal medida consiste em importante abertura da Corte Constitucional à participação democrática, questão que além de propiciar um amplo debate sobre a matéria, pode, no caso das quotas, fornecer claras informações sobre a questão para a melhor compreensão do tema pela sociedade civil (BOTELHO, 2009a, p. 51).

O edital previa, de início, o prazo até 30 de outubro de 2009 para que os interessados em participar da audiência pública apresentassem requerimento, tendo havido a prorrogação para o dia 30 de novembro do mesmo ano, conforme despacho de 27 de outubro.

Segundo consta do sítio do Supremo Tribunal Federal foram recebidos 252 (duzentos e cinquenta e dois) pedidos de inscrição, razão por que, foi necessária a adoção de critérios de seleção dos participantes, que segundo o relator da ação, Ministro Lewandowski, objetivou-se garantir a participação de diversos segmentos da sociedade, além de propiciar uma ampla variação de abordagens acerca da temática em apreciação ${ }^{18}$. Assim, deferiu-se a participação de 38 (trinta e oito) especialistas e

\footnotetext{
${ }^{17}$ Disponível no site do Supremo Tribunal Federal, In: http://www.stf.jus.br/portal/cms/verTexto.asp? servico=processoAudienciaPublicaAcaoAfirmativa. Acesso em 5 nov. 2009.

${ }^{18}$ Disponível no site do Supremo Tribunal Federal, In: http://www.stf.jus.br/portal/cms/verTexto.asp? servico=processoAudienciaPublicaAcaoAfirmativa. Acesso em 5 jan. 2010.
} 
interessados, que disporão de 15 (quinze) minutos para intervenção, não obstante, qualquer interessado, habilitado ou não, poder encaminhar, via correio eletrônico, documentos com a tese defendida, os quais serão disponibilizados no portal do Supremo Tribunal Federal ${ }^{19}$.

Ouviram-se diversos especialistas e interessados, posicionando-se favoráveis ou não ao regime de quotas. O cronograma da divisão temática desenvolveu-se da seguinte forma, sendo determinação do Ministro Relator, em despacho datado de 26 de fevereiro de $2010^{20}$ :

\section{3 de março}

(i) Instituições estatais responsáveis pela regulação e organização das políticas nacionais de educação e de combate à discriminação étnica e racial (Ministério da Educação, Secretaria Especial de Políticas de Promoção da Igualdade Racial, Secretaria Nacional de Direitos Humanos, Fundação Nacional do Índio e Comissão de Constituição e Justiça do Senado Federal), bem como pela instituição responsável por mensurar os resultados dessas políticas públicas (Instituto de Pesquisa Econômica Aplicada-IPEA).

(ii) Partes relacionadas aos processos selecionados para a audiência pública.

\section{4 de março}

Início do contraditório entre os defensores da tese de constitucionalidade e os defensores da tese de inconstitucionalidade das políticas de reserva de vaga como ação afirmativa de acesso ao ensino superior (5 defensores para cada uma das teses). Nessa data, os defensores da tese de inconstitucionalidade das políticas de reserva de vagas iniciarão o contraditório e serão seguidos pelos defensores da tese contrária.

\section{5 de março}

Manhã - Na manhã do dia 5 de março, dar-se-á continuidade ao contraditório entre os defensores das teses de constitucionalidade e de inconstitucionalidade das políticas de reserva de vagas. Nessa data, serão os defensores da tese de constitucionalidade que iniciarão o contraditório, que será encerrado pelos defensores da tese da inconstitucionalidade.

Tarde - O período da tarde do dia 5 de março será destinado à apresentação das experiências das universidades públicas na aplicação das políticas de reserva de vagas como ação afirmativa para acesso ao ensino superior. Após essas entidades, a Associação dos Juízes Federais exporá como tem julgado os conflitos decorrentes da aplicação dessas medidas. Essas exposições têm como escopo permitir que esta Corte Constitucional avalie se e em que medida as políticas de reserva de vagas no ensino superior afrontam a Constituição Federal de 1988.

O que pode ser percebido é que se possibilitou uma ampla participação de todos os interessados, fomentando-se, na medida do possível e considerados os limites

\footnotetext{
${ }^{19}$ Disponível no site do Supremo Tribunal Federal, In: http://www.stf.jus.br/portal/cms/verTexto.asp? servico=processoAudienciaPublicaAcaoAfirmativa. Acesso em 5 jan. 2010.

${ }^{20}$ Disponível no site do Supremo Tribunal Federal, In: http://www.stf.jus.br/portal/cms/verTexto.asp? servico=processoAudienciaPublicaAcaoAfirmativa. Acesso em 26 ago. 2010.
} 
naturais e custos do procedimento, que todas as visões pudessem ser levadas ao espaço público e serem objeto de discussão, crítica e consideração.

O ponto negativo, porém, na experiência, foi a baixa participação dos Ministros do Supremo Tribunal Federal. Não se pode deixar de considerar que são eles os destinatários finais das provas e argumentos produzidos na audiência pública, sobretudo se compreendermos, como faz Peter Häberle (2002, p. 36) que a Corte Constitucional é o último intérprete formalmente competente na sociedade aberta.

Em derradeiro, contudo, podemos afirmar que a questão das quotas raciais nas universidades públicas ou, ainda, de forma mais ampla a própria questão da ação afirmativa por intermédio de quotas encontra-se suspensa e, sobretudo, a mercê do Poder Judiciário, embora tenha havido a disposição da Corte de abrir-se para manifestação dos interessados.

\section{CONCLUSÕES}

A questão das ações afirmativas, em particular, daquelas medidas envolvendo quotas raciais ainda é tormentosa e, mesmo diante de uma eventual decisão favorável do Supremo Tribunal Federal quanto a constitucionalidade das medidas estatais adotadas, ainda será objeto de controvérsias perante a sociedade.

Talvez o problema resida presença ainda forte de uma ética liberal e capitalista no ideário dos brasileiros, em que subjaz um ideia de mérito individual. É o Darwinismo Social impregnado nas relações entre os indivíduos, em que o sucesso é visto tão-somente como o fruto dos méritos pessoais e o fracasso como obra da deficiência, incapacidade ou mesmo desídia do indivíduo.

Fatores de discriminação históricos, como a escravidão no Brasil, além de outras conquistas obtidas no decorrer as épocas, citando-se como exemplo, os direitos fundamentais, são deixados de lado, por não serem vistos como elementos importantes para a apreciação das medidas que envolvem as ações afirmativas.

Assim impera no Brasil uma discriminação velada, travestida de um pluralismo social que dissemina a exclusão, a separação, a pobreza e a afronta a dignidade da pessoa humana.

A história americana nos mostrou que medidas de natureza afirmativa somente foram capazes quando houve forte intervenção do Poder Judiciário. Não que a atual sociedade americana tenha se livrado das amarras racistas e discriminatórias.

Mas, somente com uma intervenção eficaz do Poder Judiciário é que discriminações e conquistas históricas foram trazidas para o debate das ações afirmativas e transformadas em decisões reconhecedoras da importância das ações afirmativas.

O Brasil encontra-se em um importante átimo de sua história, no que se refere à questão dos direitos fundamentais, das ações afirmativas e particularmente das políticas de quotas raciais, tendo em vista o julgamento em curso da ADPF n ${ }^{\circ}$ 186, no âmbito do Supremo Tribunal Federal. A importância, ainda, toma vulto considerável quando observamos que o Pretório Excelso, de maneira habermasiana, abriu o debate da questão a todos os interessados, mediante a convocação e realização de audiência pública. 
E, neste contexto, a comunidade acadêmica, juristas, estudiosos, dentre outros, têm papel importante de levar ao conhecimento da Corte Maior os elementos necessários para que ela profira decisão que promova a efetiva igualdade, a inclusão, a quebra das barreiras raciais e a dignidade da pessoa humana.

Contudo, o processo de abertura do Supremo Tribunal Federal parece estar apenas no começo, sobretudo se considerarmos a baixa participação dos Ministros do Pretório Excelso na audiência pública realizada, o que certamente contribuiu negativamente para o processo de abertura democrática da Corte.

\section{BIBLIOGRAFIA}

ABRAMOVAY, Miriam et. al. Juventude, violência e vulnerabilidade social na América Latina: desafios para políticas públicas. Brasília: Unesco, BID, 2002, p. 28-31.

ANJOS FILHO, Robério dos. Minorias e grupos vulneráveis: uma proposta de distinção. In: ROCHA, João Carlos de Carvalho; HENRIQUES FILHO, Tarcísio Humberto Parreiras; CAZETTA, Ubiratan (Coords.). Direitos humanos: desafios humanitários contemporâneos. Belo Horizonte: Del Rey, 2008, p. 341-380.

ARAÚJO, Luiz Alberto David. A proteção constitucional das pessoas portadoras de deficiência: algumas dificuldades para efetivação dos direitos. In: SARMENTO, Daniel; IKAWA, Daniela; PIOVESAN, Flávia (coords.). Igualdade, diferença e direitos humanos. Rio de Janeiro: Lúmen Júris, 2008, p. 911-923.

BARACHO, José Alfredo de Oliveira. Teoria da igual proteção (equal protection). In: Direito Processual Constitucional: aspectos contemporâneos. Belo Horizonte: Fórum, 2008, p. 97-102.

BARROSO, Luís Roberto. Temas de Direito Constitucional. Rio de Janeiro: Renovar, tomo III, 2005, p. 61-77.

BELLINTANI, Leila Pinheiro. Ação afirmativa e os princípios do direito: a questão das quotas raciais para ingresso no ensino superior no Brasil. Rio de Janeiro: Lumen Juris, 2006.

BOTELHO, Marcos César. Democracia e jurisdição: a legitimidade da jurisdição constitucional na democracia procedimental de Jürgen Habermas. Brasília: Revista Direito Público, $\mathrm{n}^{\circ}$ 19, jan./fev. 2008, p. 218-233.

A corte constitucional como espaço público por excelência: considerações em Habermas e Häberle. Brasília: Revista Jurídica Consulex, Ano XIII, n 294, 15 de abril de 2009a, p. 50-51.

A equiprimordialidade entre autonomia pública e privada: uma proposta procedimentalista para a eficácia dos direitos fundamentais nas relações jurídico-privadas. Londrina: Revista Eletrônica do Direito Privado. Universidade Estadual de Londrina. Vol. 2, $\mathrm{N}^{\circ}$ 1, 2009b, p. 1-23.

BUCCI, Maria Paula Dallari. O conceito de política pública em direito. In: BUCCI, Maria Paula Dallari (org.). Políticas públicas: reflexões sobre o conceito jurídico. São Paulo: Saraiva, 2006, p. 1-50.

CARBONELL, Miguel. Constitucionalismo, minorias y derechos. In: CARBONELL, Miguel; PARCERO, Juan A. Cruz; VÁSQUEZ, Rodolfo (coords.). Derechos sociales y derechos de las minorias. México, D.F.: Universidad Nacional Autónoma de México, 2000, p. 247-270.

Estudio preliminar. La igualdad y los derechos humanos. In: CARBONELL, Miguel (coord.). El princípio constitucional de igualdad: lecturas de introducción. México, D.F.: Comisión Nacional de los Derechos Humanos, 2003, p. 9-29. 
CUNHA, José Marcos Pinto da. Um sentido para a vulnerabilidade sociodemográfica nas metrópoles paulistas. Novos Estudos Jurídicos, vol. 13, n. 2, jul./dez., 2008. p. 77-92.

FRASER, Nancy. A justiça social na globalização: redistribuição, reconhecimento e participação. Eurozine, 2003, p. 1-11.

GONÇALVES, Alcindo. Políticas públicas e a ciência política. In: BUCCI, Maria Paula Dallari (org.). Políticas públicas: reflexões sobre o conceito jurídico. São Paulo: Saraiva, 2006, p. 75-96.

HABERMAS, Jürgen. Constitutional democracy: a paradoxical union of contradictory principles? Political Theory, v. 29, n. 6, december, 2001, p. 766-781. 2004.

A inclusão do outro: estudos de teoria política. 2. ed. São Paulo: Edições Loyola,

HÄBERLE, Peter. Hermenêutica constitucional: A sociedade aberta de intérpretes da constituição: contribuição para a interpretação pluralista e "procedimental" da constituição. Porto Alegre: Sérgio Fabris Editor, 2002.

HARTMAN, Gary; MERSKY, Roy M.; TATE, Cindy L. Landmark supreme court cases. New York: Facts On File, 2004, p. 34-39.

HONNETH, Axel. Sofrimento de indeterminação: uma reatualização da filosofia do direito de Hegel. São Paulo: Editora Singular, Editora Esfera Pública, 2007.

KAUFMANN, Roberta Fragoso Menezes. Ações afirmativas à brasileira: necessidade ou mito? Uma análise histórico-jurídico-comparativa do negro nos Estados Unidos da América e no Brasil. Porto Alegre: Livraria do Advogado, 2007.

KELLOUGH, J. Edward. Understanding affirmative action: politics, discrimination, and the search for justice. Washington, D.C.: Georgetown University Press, 2006.

LOPES, Ana Maria D’Ávila. Multiculturalismo, minorias e ações afirmativas: promovendo a participação política das mulheres. Pensar, Fortaleza, v. 11, fev., 2006, p. 54-59.

MARTINEZ, Gregorio Peces-Barba. Lecciones de derechos fundamentales. Madrid: Dykinson, 2004, pp. 181-189.

MELLO, Celso Antônio Bandeira de. Conteúdo jurídico do princípio da igualdade. 3. ed. São Paulo: Malheiros, 2009.

MELLO, Marco Aurélio Mendes de Farias. Óptica constitucional, a igualdade e as ações afirmativas. Revista da Escola Nacional de Magistratura, v. 1, n. 1, abr., 2006, p. 82-91.

MENEZES, Paulo Lucena. A ação afirmativa (affirmative action) no direito norte-americano. São Paulo: Revista dos Tribunais, 2001.

MOEHLECKE, Sabrina. Ação afirmativa: história e debates no Brasil. Cadernos de Pesquisa, n. 117, nov. 2002. p. 197-217.

PIOVESAN, Flávia. Ações afirmativas da perspectiva dos direitos humanos. Cadernos de Pesquisa, v. 35, n. 124, jan./abr. 2005. p. 43-55. 2006.

Direitos Humanos e o Direito Constitucional Internacional. 7. ed. São Paulo: Saraiva,

PROGRAMA NACIONAL DE DIREITOS HUMANOS-PNDH. $11^{\text {a }}$ Conferência Nacional dos Direitos Humanos. Texto-base. Brasília: Secretaria Especial dos Direitos Humanos, 2008.

QUEIROZ, Cristina. Direito Constitucional: as instituições do estado democrático e constitucional. São Paulo: Revista dos Tribunais; Coimbra: Editora Coimbra, 2009, p. 359-389. 
ROSENFELD, Michel. Hacia una reconstrucción de la igualdad constitucional. In: CARBONELL, Miguel (coord.). El princípio constitucional de igualdad: lecturas de introducción. México, D.F.: Comisión Nacional de los Derechos Humanos, 2003, p. 69-103.

ROTHENBURG, Walter Claudius. Igualdade material e discriminação positiva: o princípio da isonomia. Novos Estudos Jurídicos, vol. 13, n. 2, jul./dez. 2008. p. 77-92.

SANCHÍS, Luis Prieto. Ley, princípios, derechos. Madrid: Dykinson, 1998, pp. 81-96.

SOUZA, Celina. Políticas públicas: uma revisão da literatura. Sociologias, Porto Alegre, ano $8, n^{\circ} 16$, jul./dez. 2006. p. 20-45.

SUB JUDICE - Justiça e Solidariedade. Lisboa: Fundação Luso-Americana para o Desenvolvimento, $\mathrm{n}^{\circ}$ 12, jan./jun. 1998. p. 77-81.

SUNSTEIN, Cass R. A constituição parcial. Belo Horizonte: Del Rey, 2009.

TURNER, Bryan S. (ed). The Cambridge dictionary of sociology. Cambridge; Cambridge University Press, 2006.

VELLOSO, Carlos Mário da Silva. Os tratados na jurisprudência do Supremo Tribunal Federal. Revista de Informação Legislativa, a. 41, n. 162, abr./jun., 2004. p. 35-45.

VILAS-BÔAS, Renata Malta. Ações afirmativas e o princípio da igualdade. Rio de Janeiro: América Jurídica, 2003.

VILLORO, Luis. Sobre relativismo cultural y universalismo ético. En torno a ideas de Ernesto Garzón Valdés. In: CARBONELL, Miguel; PARCERO, Juan A. Cruz; VÁSQUEZ, Rodolfo (coords.). Derechos sociales y derechos de las minorias. México, D.F.: Universidad Nacional Autónoma de México, 2000, p. 171-184.

YTURBE, Corina. Multiculturalismo y derechos. México, D.F.: Instituto Federal Electoral, 1998, p. 37-46.

ZAGREBELSKY, Gustavo. El derecho dúctil. Madrid: Editorial Trotta, 2005. 